\title{
Extracellular matrix components as diagnostic tools in inflam- matory bowel disease
}

\author{
Laura Golusda 1,2, Anja A. Kühl ${ }^{1}$, Britta Siegmund ${ }^{2}$ and Daniela Paclik 1,2*
}

1 Charité - Universitätsmedizin Berlin, corporate member of Freie Universität Berlin and Humboldt Universität zu Berlin, iPATH.Berlin, Campus Benjamin Franklin

2 Charité - Universitätsmedizin Berlin, corporate member of Freie Universität Berlin and Humboldt Universität zu Berlin, Medizinische Klinik für Gastroenterologie, Infektiologie und Rheumatologie (einschl. Arbeitsbereich Ernährungsmedizin), Campus Benjamin Franklin

* Correspondence: daniela.paclik@charite.de; Hindenburgdamm 30, D-12200 Berlin Tel.: +49 30-450-514-345

\begin{abstract}
Simple Summary: For decades, the extracellular matrix (ECM) has been defined as a structure component playing a rather neglected role in the human body. In the recent years, research has shed light on the role of ECM within cellular processes including proliferation, migration, and differentiation as well as in inflammation. In inflammation, ECM composition is constantly being remodeled and undergoes dynamic and rapid changes. Tracking these changes could serve as a novel diagnostic tool. Inflammatory bowel disease is accompanied by complications like fibrosis, stenosis and fistulas. All these structural complications involve excessive synthesis or degradation of ECM. With this review we explored whether the analysis of ECM composition can be of support in diagnosing inflammatory bowel disease and whether changes within ECM can help to predict early on a complicated disease course.
\end{abstract}

Abstract: Work from the last years indicate that the extracellular matrix (ECM) plays a direct role in various cellular processes including proliferation, migration and differentiation. Besides homeostatic processes, its regulatory function in inflammation becomes more and more evident. In inflammation like inflammatory bowel disease, the ECM composition is constantly remodeled which can result in a structuring of fistulizing disease course. Thus, tracking early ECM changes might bear the potential to predict the disease course. In this review, we will provide an overview of relevant diagnostic methods focusing on ECM changes.

Keywords: extracellular matrix; glycosaminoglycans; inflammatory bowel disease; ulcerative colitis; Crohn's disease; fibrosis; stenosis; magnetic resonance imaging; elastography; histopathology

\section{Introduction}

The main forms of inflammatory bowel disease (IBD) are ulcerative colitis (UC) and Crohn's disease (CD). Both are chronic inflammatory conditions with an altered extracellular matrix (ECM). The diagnosis of $\mathrm{UC}$ and $\mathrm{CD}$ is a lifelong threat as the available therapies treat and ease the symptoms but do not cure the disease. It is accepted that IBD results from an exaggerated mucosal immune response in genetically predisposed individuals. Environmental factors trigger this response and a leaky epithelial barrier is either 0cause or consequence. The onset of IBD occurs in late adolescence and early adulthood affecting all aspects of life. The incidence and prevalence of IBD is increasing worldwide just as the total number of related deaths ${ }^{1}$. The western Europe region had the highest age-standardized death rate in $2017^{1}$. Overall, an estimated 1.3 million people in Europe 
suffer from IBD, which equals $0.2 \%$ of the European population ${ }^{2}$. The amount of direct healthcare costs per patient per year reach up to $€ 2,000$ (UC) and $€ 3,500(\mathrm{CD})$, respectively 2. It is still not clear whether changes in ECM occur at an early disease stage triggering inflammation and contributing to chronicity or whether changes develop at later disease course that are caused by chronic and excessive inflammation. Complicated disease (stricturing or penetrating disease behavior) is a consequence of altered ECM requiring intervention like balloon dilation or surgery including strictureplasty or resection ${ }^{3}$. Over $50 \%$ of CD patients and up to $11 \%$ of UC patients experience fibrostenotic complications ${ }^{4}$. These complications are accompanied by changes in the ECM. Currently the diagnosis of IBD is based on a multitude of parameters from clinics, laboratory, imaging, endoscopy and histopathology 5,6 . However, the currently available tools to predict disease course have not entered clinical routine yet ${ }^{7}$. Thus, an in-depth analysis of ECM over the course of the disease might provide a novel tool to fill this gap.

The core components of the ECM are fibronectin, collagens, laminins and proteoglycans. Proteoglycans have a protein core to which sulfated glycosaminoglycans (s-GAGs) are attached. The attached s-GAGs are linear polysaccharides, which are highly negatively charged. They are build out of disaccharide building blocks. Based on the degree of sulfation, the position of sulfation, the linkage between each and the type of monomeric unit, they are classified into the following groups: chondroitin sulfate/dermatan sulfate (CS/DS), keratan sulfate (KS) and heparin/heparan sulfate (HS) ${ }^{8,9}$. Hyaluronic acid is the only non-sulfated GAG present in the ECM. GAGs take part in cell-matrix interactions and s-GAGs are strongly expressed in the ECM of intestinal tissues. Throughout the gastrointestinal tract, s-GAG are found in the subepithelial basal membrane, the vascular endothelium and the ECM of the (sub)mucosa ${ }^{10}$. Naba et al. characterized the matrisome that defines all colon tissue-specific proteins in the mouse colon that are part of or associated with the ECM ${ }^{11,12}$.

This review presents the latest findings on ECM changes in IBD and by this illustrates how these could not only serve as a tool to monitor but rather to predict the disease course.

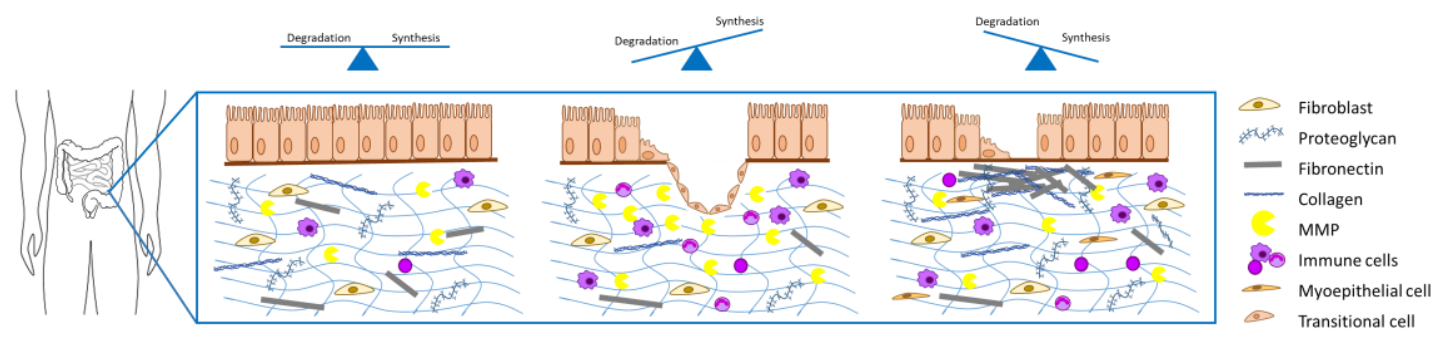

Figure 1: Changes in ECM composition during a chronic disease course. The panels shown illustrate homeostasis (left), fistulizing disease (middle) and structuring disease (right).

\section{Materials and Methods}

A literature search in MEDLINE using the electronic database PubMed was conducted to identify GAG/ECM-associated diagnostic tools in IBD. The following search terms were included: ((inflammatory bowel disease) OR (ulcerative colitis) OR (Crohn's disease)) AND (diagnosis) AND ((magnetic resonance imaging) OR (sonography) OR (ultrasound) OR (elastography) OR (histology) OR (histopathology)) AND ((extracellular matrix) OR (glycosaminoglycan)) AND (fibrosis OR stenosis OR stricture OR fistula) as well as (contrast-enhanced mri) AND (bowel) OR (intestine). Included were studies in adult humans of the past 10 years. 


\section{Results}

\subsection{In-vivo Imaging}

Several types of imaging are required for diagnosing UC and CD. This generally includes colonoscopy as well as initially also small bowel magnetic resonance imaging (MRI) as well as upper endoscopy to determine the disease pattern and the type of disease in the individual patient. Computed tomography (CT) should be restricted to emergency situations to limit radiation exposure. Furthermore ultrasound (US) is nowadays frequently used for follow-up evaluation ${ }^{13}, 14$. Employing CT enterography in order to predict small intestinal fibrosis in CD patients revealed that the only predictive parameter was mesenteric hypervascularity although this parameter correlates better with inflammation than fibrosis ${ }^{15}$. Combining CT enterography with positron emission tomography [PET] (PET/CT) was as accurate as PET/magentic resonance-enterography in detecting strictures and bowel wall thickening ${ }^{16}$. However, for both techniques, the accuracy depended on the bowel segment. The accuracy was low for duodenum and colon and highest for the terminal ileum and cecum as well as ileocolonic anastomosis ${ }^{16}$. For the detection of fistulas, the sensitivity, specificity and accuracy of small intestine contrast ultrasonography (SICUS) is comparable to CT enteroclysis and surgical findings ${ }^{17}$. SICUS is also accurate in detecting strictures and their extension in the proximal and distal small intestine as well as fistulas and abscesses when compared to surgical and histological findings ${ }^{18}$. Compared to intraoperative findings, SICUS is more accurate in assessing fistulas, abscesses and strictures than dilatations and bowel wall thickening ${ }^{19}$. The treatment response was monitored in a multicenter study including patients with active CD by US assessing bowel wall thickness, vascularization, and contrast-agent uptake as well as fistulas, abscesses and stenoses ${ }^{20}$. For determining CD activity, Novak et al. developed and validated an US score (simple sonographic score) ${ }^{21}$. This score might have been too simple and was not widely accepted. Besides this the Limberg score is widely used to assess disease activity with US ${ }^{22}$. A recent study proposed a regression model based on multimodal multi-parametric ultrasound to assess CD activity ${ }^{23}$. In order to differentiate between inflammation and fibrosis, Bhatnagar et al. compared sonographic features with histomorphology in CD patients ${ }^{24}$. Their study revealed that thickness of the mucosal layer rather than bowel wall thickness correlates with acute inflammation, chronic inflammation and fibrosis ${ }^{24}$. Fibrosis was associated with reduced submucosal echogenicity, increased submucosal echogenicity with hypoechoic bands and an ill-defined submucosa ${ }^{24}$.

The first contrast-enhanced MRI was performed in $1981^{25}$. Oral ferric chloride and inhaled oxygen was used. Resulting in altered spin-lattice relaxation time of the fundus and was suggested to be useful as a bowel-labeling agent ${ }^{25}$. Since 1988, the paramagnetic contrast agent Gadolinum-diethylene triamine pentaacetic acid (Gd-DTPA) has been in clinical application in Germany, the US and Japan ${ }^{26}$. Laniado et al. were able to demonstrate safety as well as effective imaging by orally administered Gd-DTPA and Mannitol 27. In 1992, the first patient received Gd-DTPA intravenously (i.v.) ${ }^{28}$. Intravenous Gd-DPTA administration improved MRI with regard to detecting disease complications and extent of bowel involvement ${ }^{29}$. Distribution of i.v. injected Gd-based contrast agents is associated with blood supply but there is no tissue targeting or specificity 30. Contrast agents targeting extracellular matrix for detection of aberrant matrix formation are still in the preclinical phase. Stable plaque formation in atherosclerosis is associated with ECM accumulation ${ }^{31}$, and has been visualized by very small superparamagnetic nanoparticles ${ }^{32}$. ECM components like collagen or fibrin-fibronectin complexes were targeted in models of liver fibrosis and colorectal cancer ${ }^{33,34}$. To our knowledge, there is no data available for ECM-targeting contrast agents in models of intestinal fibrosis. A prospective multicenter study compared the diagnostic accuracy of MR enterography and US in small bowel CD and concluded MR enterography more sensitive and more specific ${ }^{35}$. Compared to SICUS, MR enterography is more accurate in 
assessing fistulas and strictures while comparably accurate in assessing abscesses and dilatations ${ }^{19}$. Additionally, contrast-enhanced MR enterography is preferred to biochemical markers, as a significant number of patients with quiescent disease have high fecal calprotectin levels ${ }^{36}$. Furthermore, MR imaging could accurately detect and distinguish varying degrees of bowel fibrosis with or without coexisting inflammation. Magnetization transfer MRI could accurately detect the severity of bowel fibrosis in stricturing CD but not the inflammatory component within the stricture ${ }^{37}$, whereas fibrotic and inflammatory strictures could be differentiated from purely inflammatory strictures ${ }^{37}$. With reasonable accuracy, an area under the ROC curve of $>0.7$, MRI could distinguish inflammation/edema and muscular hypertrophy from fibrosis in ileal CD in a retrospective study ${ }^{38}$.

Table 1. Diagnostic imaging methods to detect inflammation and complications in IBD.

\begin{tabular}{llc}
\hline Method & Diagnosis & References \\
\hline Ultrasound & $\begin{array}{l}\text { Bowel wall thickening, lesions, hypervascularity, } \\
\text { strictures, dilatation }\end{array}$ & 39-41 \\
\hline Computed tomography & Mesenteric hypervascularity, fistulae, abscesses & 15,39 \\
\hline PET/CT & $\begin{array}{l}\text { Strictures, bowel wall thickening, inflammatory activ- } \\
\text { ity }\end{array}$ & 16,42 \\
\hline \multirow{2}{*}{ Magnetic resonance imaging } & $\begin{array}{l}\text { Strictures, fistulae, abscesses, dilatations, edema, mus- } \\
\text { cular hypertrophy }\end{array}$ & 19,38 \\
\hline SICUS & Strictures, fistulae, abscesses & 18,19 \\
\hline
\end{tabular}

Ten years ago, a small number of CD patients underwent ultrasound elastography (USE) prior to elective resection of small intestinal strictures in a pilot study. US-E was guided by MRI and CT and the scanning included diseased stenotic and adjacent unaffected small intestine. This pilot study revealed that lower strain values indicate stiffer tissue in stenotic than unaffected bowel ${ }^{43}$. Histopathology confirmed predominantly fibrotic strictures with submucosal collagen depositions, while stenotic tissue was characterized by fibrosis and mild to moderate inflammation ${ }^{43}$. US-E is a feasible and reproducible technique for assessing ileal wall fibrosis in CD patients as the strain ratio correlates significantly with the severity of fibrosis ${ }^{44}$. US-E detects fibrosis in ileal/ileocolonic segments of CD patients via increased muscular layer thickness and collagen deposition 45 , but is still not able to differentiate fibrosis from inflammation even when contrast enhanced ${ }^{46,47}$. Shear-wave elastography (SWE) is a novel technique that allows for quantitative estimation of tissue stiffness. While resected bowel segments showed ex vivo a higher mean shear-wave speed in high-grade fibrosis than low-grade fibrosis with minimal overlap ${ }^{48}$, there was no relationship of fibrosis and SWE in vivo ${ }^{49}$. Lu et al. found that fibrosis was not the major component in bowel wall thickening and strictured bowel segments but rather muscular hypertrophy ${ }^{49}$. When combining SWE and the Limberg score for bowel vascularization high- and low-grade inflammation as well as high- and low-grade fibrosis could be discriminated ${ }^{50}$. SWE seems also feasible for determining disease activity in UC while it is rather discriminative in the left- than in the right-sided colon 51 .

Frequent clinical applications of magnetic resonance elastography (MRE) in the abdomen are liver diseases, whereas the bowel is technically challenging owing to its location, mobility, and physiological motion ${ }^{52}$. These challenges were tackled in a prospective pilot study. Here, shear-wave speed and loss angle representing stiffness and solidfluid behavior were studied in IBD patients and healthy controls ${ }^{53}$. Both were increased in IBD patients compared to controls, however, there was no significant difference between UC and CD ${ }^{53}$. Further studies are needed for an assessment of intestinal fibrosis. 


\subsection{Histopathology}

In UC, histopathology is required for diagnosis, assessment of disease activity, and identification of dysplasia and cancer ${ }^{14}$. Microscopic features include mucosal architecture, lamina propria cellularity, neutrophil granulocyte infiltration, and epithelial abnormality ${ }^{14}$. Microscopic features in diagnosing $\mathrm{CD}$ are discontinuous chronic inflammation and crypt distortion as well as granulomas ${ }^{13}$. In UC, any colonic stricture is suspicious of cancer and requires evaluations as such ${ }^{14}$. In contrast, structuring disease in CD can occur even in the absence of cancer. Distinguishing structuring disease from cancer can be a diagnostic challenge ${ }^{13}$. However, an international consortium developed and validated a stricture histopathology scoring system, in order to enable the development of novel biomarkers and support the construction of imaging endpoints for clinical trials in stricturing $\mathrm{CD}^{54}$. The consensus was reached for evaluating tissue sections stained with hematoxylin and eosin (H\&E) but not using Movat or elastin stains. No consensus could be reached for the need of trichrome stain ${ }^{54}$. The Movat stain is a pentachrome stain and differentiates elastic, collagen and reticular fibers as well as muscle and fibrin ${ }^{55}$, whereas a trichrome staining allows for differentiation of muscle fibers, collagen and keratin ${ }^{56}$. Hence, ECM components or glycosaminoglycans are not yet part of the clinical routine for diagnosis or follow-up but are potential candidates in histopathological assessment. For example, serum levels of matrix metalloproteinase (MMP)-9 have been shown to be increased in UC patients. In line, within the mucosa immunohistochemically detected MMP-9 expression increases with severity ${ }^{57}$. The advantage of histopathology is the spatial allocation of protein expression. For instance, Fonseca-Camarillo et al. identified upregulation of extracellular matrix metalloproteinase inducer (EMMPRIN, CD147) in patients with active $\mathrm{UC}$ and mononuclear and endothelial cells being the main producers 58. Numbers of CD147-positive cells expressing MMP-23 and MMP-10 are increased in active UC compared to active $C D$ 58. Analyzing stenotic and inflamed ileum from $C D$ patients revealed enhanced CD3-positivity in the inflamed region and increased collagen-positivity in the stenotic region ${ }^{59}$. The increased collagen content was accompanied by increased losyl oxidase (LOX) involved in the process of collagen deposition linking collagen to elastin but also interacting with fibronectin ${ }^{59}$. Also, CD20-positive cells were increased in fistulizing versus stenosing $C D$. The ECM glycoprotein tenascin $C$ was also upregulated in the mucosa of patients with UC and CD compared to controls 60 . Tenasin $C$ is mainly expressed in the lamina propria ${ }^{60}$. Additionally, mucosal mRNA expression has been associated with treatment response, tenascin $\mathrm{C}$ mRNA expression was higher in UC patients nonresponsive to infliximab therapy ${ }^{60}$.

\subsection{Serological markers}

As the balance of degradation and production of ECM is disrupted, components of the degraded ECM can be found in the peripheral blood. Therefore, assessment of degraded ECM components in the serum has diagnostic potential. Assessing s-GAGs, hyaluronan and soluble CD138 in the serum revealed no changes in CD patients compared to healthy controls whereas hyaluronan was significantly increased in UC patients and correlated with Mayo score and thus disease severity ${ }^{61}$. Hence, this difference might help to distinguish UC from CD. However, the data are currently limited to treatment-naïve patients. Steroid therapy resulted in an increase of hyaluronan and was statistically not significantly different from untreated UC or adalimumab-treated UC patients ${ }^{61}$. Specific ECM degradation proteins with diagnostic value like MMP-9 degraded type III collagen fragment $\mathrm{C} 3 \mathrm{M}$ has been associated with penetrating $\mathrm{CD}{ }^{62}$. Serum levels of $\mathrm{C} 3 \mathrm{M}$ were increased in patients with penetrating $C D$ when compared to healthy controls but neither to non-penetrating or stricturing disease nor to perianal fistula ${ }^{62}$. Mortensen et al. also defined biomarker combinations to discriminate $\mathrm{CD}$ from $\mathrm{UC}$ and $\mathrm{UC}$ from nonIBD controls ${ }^{63}$. Serum levels of VICM (MMP-2/8 degraded and citrullinated-vimentin), C3M and C4M (MMP-9 degraded collagen type IV) discriminate CD from UC, and C1M (MMP-9 degraded collagen type I) as well as C3M discriminate UC from non-IBD ${ }^{63}$. 
Compared to healthy controls, the tissue inhibitor of metalloproteinase 1 TIMP-1 was increased in the serum of patients with $\mathrm{UC}$ or $\mathrm{CD}$ and higher in active disease allowing also for disease activity assessment ${ }^{64}$. Using serum glycoproteome profiles, Stidham et al. identified two biomarkers which distinguish inflammatory from fibrostenotic phenotypes of $\mathrm{CD}{ }^{65}$. Both cartilage oligomeric matrix protein (COMP) and hepatocyte growth factor activator (HGFA) showed $\geq 20 \%$ change in relative abundance between fibrotic and inflammatory disease types ${ }^{65}$. Van Haaften et al. identified that serum levels of formation and degradation products of collagens can serve to differentiate penetrating and non-stricturing/non-penetrating as well as stricturing $\mathrm{CD}$ in the terminal ileum ${ }^{66}$. Other studies comparing different ECM components found that a strong increase of extracellular matrix protein 1 (ECM1) in CD patients is correlated with a higher risk to change from inflammatory phenotype to stricturing phenotype ${ }^{67}$. Unfortunately, for none of the markers exists a standard value which clearly defines the disease status or activity.

Another group of serum makers are anti-microbial antibodies against specific bacteria, bacterial membrane components or anti-glycans, like anti-Saccaromyces-cervisiae, antiEscherichia-coli outer membrane porine $\mathrm{C}$, anti-flagellin, anti-laminaribioside carbohydrate antibodies, antimannobioside carbohydrate antibodies, antichitobioside carbohydrate antibodies, antichitin antibody, and antilaminarin antibody $68-70$. Unfortunately, none of the markers is directly associated and correlated with fibrostenotic stricture formation ${ }^{71}$.

Additionally, some growth factors have been studied as possible biomarkers to detect early ECM alterations and fibrosis. Among them are vascular endothelial growth factor (VEGF), platelet-derived growth factor (PDGF), fibroblast growth factor (bFGF) and human chitinase 3-like 1 , influencing angiogenesis, fibrogenesis, myofibroblast proliferation and myofibroblast-induced collagen secretion ${ }^{72}$. VEGF and bFGF both promoting angiogenesis, tissue repair and fibroblast proliferation are significantly increased in serum of $\mathrm{CD}$ patients and correlate with bowel wall thickness ${ }^{73}$. The expression of PDGF is enhanced at sites of inflammation and fibrosis ${ }^{74}$ as well as in the serum of CD patients ${ }^{75}$. None of the markers can be used to predict fibrostenotic risk but are rather markers for the severity of fibrotic changes.

Besides components of ECM, growth factors and bacterial components, a potential tool to diagnose fibrosis is the detection of epigenetic markers like microRNA (miR). These short, non-coding RNAs are regulating expression of target genes at a post-transcriptional level. One of those, miR-200b was shown to be increased in liver fibrosis ${ }^{76}$. When comparing CD patients with and without fibrostenotic complications, there is a significant difference in serum levels of miR-200b between the groups ${ }^{76}$. Mehta et al. revealed that a down-regulation of miR-200b in intestinal epithelial cells is associated with epithelial to mesenchymal transition ${ }^{77}$. Furthermore, low serum levels of miR-19 ${ }^{78}$ and miR$29 \mathrm{~b}^{79}$ could be correlated with a stricturing phenotype in CD patients. Currently there are no epigenetic biomarkers which allow the early prediction of a high risk to develop fibrostenotic complications and further studies to characterize their role are essential. To summarize this paragraph, a number of potential biomarkers have been described to identify fibrostenotic complications. Still, due to a low sensitivity and specificity none of them has entered clinical routine.

\section{Discussion}

Changes in the ECM trigger inflammation and contribute to chronicity in IBD. This is reflected by the presence of fibrosis and stricturing disease in about $11 \%$ of UC patients as well as over $50 \%$ of $\mathrm{CD}$ patients. These complications often require surgical intervention. We here review the latest developments in diagnosing ECM changes in order to assess complicated disease, but also to monitor mucosal healing or differentiate CD from UC. 
Early and accurate diagnosis of a complicated disease course is crucial for assessment and management of these patients. For example, intestinal fibrosis negatively influences the response to therapy with biologicals 80,81 .

The gold standard for diagnosing disease remains endoscopy. Cross-sectional imaging techniques add in particular information with regards to the small bowel as well as to complications including abscess and fistulizing disease. There is European consent, that the use of CT should be limited to emergency due to radiation exposure. Thus, MRI should present the standard technique and has a high contrast resolution providing anatomical details without ionizing radiation, but is time- and cost-intensive. Additionally, most contrast agents used in MRI contain gadolinium which can accumulate in tissues regardless of renal function ${ }^{82}$. Against a background of IBD patients having an increased risk to develop chronic kidney disease ${ }^{83}$ and of patients with impaired renal function developing in rare cases gadolinium-associated systemic fibrosis ${ }^{84}$ radiologist have to balance risks and benefits of gadolinium-enhanced MRI.

The technique of US is rapid, safe and easy to use. Recent studies have provided convincing evidence that US can be performed in a reproducible manner, thus, the former argument that it strongly dependent on the examiner is outdated ${ }^{85}$. Elastography is also non-invasive and the advantages of US apply to elastography. Shear wave elastography requires fasting of the patients in order to reduce bowel content and blood flow. US-E strain ratio not only depends on the degree of pressure exerted by the US probe ${ }^{44}$, but the mesenteric tissue surrounding the bowel wall serves as control. This control might be misleading as hyperplasia of mesenteric fat itself already affects the strain ratio. Hyperplastic mesenteric fat wrapping around the circumference of the intestine (creeping fat) is a common feature in CD ${ }^{86,87}$. Additionally, mesenteric and creeping fat is inflamed in CD, 88 providing misleading strain ratios ${ }^{44}$. The application field of elastography is limited to selected bowel segments and allows no cross-sectional imaging ${ }^{89}$. Multimodal imaging would be optimal for assessing the disease, the disease activity and complications, but one has to keep in mind that bowel peristaltic negatively influences all imaging techniques. There is no reference standard in the diagnosis of IBD but as initial diagnostic tool radiologic visualization combined with a follow-up via US are widely used to diagnose and evaluate IBD ${ }^{5}$.

In-situ imaging using histopathology provides a clear picture of the intestinal tissue but is only a snapshot, and is limited to the surface layers when taken as biopsy. Histopathology in combination with endoscopy gives a good overview of stricturing, mucosal surface and gut motion and is one of the most important diagnostic strategies. One disadvantage is that not all segments can be reached and the view is restricted to the luminal surface. In this regard adding insult to injury during diagnosis, noninvasive diagnostic tools are favorable.

Especially using serological biomarkers present a minimal invasive and fast approach. Various ECM-related biomarkers not only diagnose IBD but also differentiate CD from UC. But due to a low sensitivity and specificity none of them has entered clinical routine. Besides this, serum biomarkers bear the risk of capturing ECM changes in other organs. Since, IBD is associated with extraintestinal manifestations like rheumatological, musculoskeletal, hepatological and dermatological manifestations but also arthropathies and uveitis are frequent ${ }^{90}$. Nevertheless, additional assessment of ECM changes provides a great potential tool in IBD diagnosis.

\section{Conclusions}

Various methods and techniques are available for diagnosis of $\mathrm{UC}$ and $\mathrm{CD}$ as well as the assessment of disease activity and complications. Every technique has its advantages and accuracy but also implies disadvantages and inaccuracies. There is no one-size-fitsall. The optimal treatment of IBD patients should aim at a multimodal approach. Some techniques and approaches have not made it into the clinic yet and need further development and validation. Involving the extracellular matrix and its synthesis, changes and 
degradation provides a potential toolbox to monitor disease course and phenotype over time.

Funding: This research was funded by German Research Foundation, grant number SFB1340-TP B06 to AAK and BS as well as SFB 1449 to BS.

Conflicts of Interest: BS has served as consultant for Abbvie, Arena, BMS, Boehringer, Celgene, Falk, Janssen, Lilly, Pfizer, Prometheus and Takeda and received speaker's fees from Abbvie, CED Service GmbH, Falk, Ferring, Janssen, Novartis, Pfizer, Takeda [served as representative of the Charité].

\section{References}

1. Collaborators, G. B. D. I. B. D., The global, regional, and national burden of inflammatory bowel disease in 195 countries and territories, 1990-2017: a systematic analysis for the Global Burden of Disease Study 2017. Lancet Gastroenterol Hepatol 2020, 5 (1), 1730.

2. Zhao, M.; Gonczi, L.; Lakatos, P. L.; Burisch, J., The burden of inflammatory bowel disease in Europe in 2020. J Crohns Colitis 2021.

3. Bemelman, W. A.; Warusavitarne, J.; Sampietro, G. M.; Serclova, Z.; Zmora, O.; Luglio, G.; de Buck van Overstraeten, A.; Burke, J. P.; Buskens, C. J.; Colombo, F.; Dias, J. A.; Eliakim, R.; Elosua, T.; Gecim, I. E.; Kolacek, S.; Kierkus, J.; Kolho, K. L.; Lefevre, J. H.; Millan, M.; Panis, Y.; Pinkney, T.; Russell, R. K.; Shwaartz, C.; Vaizey, C.; Yassin, N.; D'Hoore, A., ECCO-ESCP Consensus on Surgery for Crohn's Disease. J Crohns Colitis 2018, 12 (1), 1-16.

4. Rieder, F.; Fiocchi, C.; Rogler, G., Mechanisms, Management, and Treatment of Fibrosis in Patients With Inflammatory Bowel Diseases. Gastroenterology 2017, 152 (2), 340-350 e6.

5. Maaser, C.; Sturm, A.; Vavricka, S. R.; Kucharzik, T.; Fiorino, G.; Annese, V.; Calabrese, E.; Baumgart, D. C.; Bettenworth, D.; Borralho Nunes, P.; Burisch, J.; Castiglione, F.; Eliakim, R.; Ellul, P.; Gonzalez-Lama, Y.; Gordon, H.; Halligan, S.; Katsanos, K.; Kopylov, U.; Kotze, P. G.; Krustins, E.; Laghi, A.; Limdi, J. K.; Rieder, F.; Rimola, J.; Taylor, S. A.; Tolan, D.; van Rheenen, P.; Verstockt, B.; Stoker, J.; European, C. s.; Colitis, O.; the European Society of, G.; Abdominal, R., ECCO-ESGAR Guideline for Diagnostic Assessment in IBD Part 1: Initial diagnosis, monitoring of known IBD, detection of complications. J Crohns Colitis 2019, 13 (2), 144-164.

6. Sturm, A.; Maaser, C.; Calabrese, E.; Annese, V.; Fiorino, G.; Kucharzik, T.; Vavricka, S. R.; Verstockt, B.; van Rheenen, P.; Tolan, D.; Taylor, S. A.; Rimola, J.; Rieder, F.; Limdi, J. K.; Laghi, A.; Krustins, E.; Kotze, P. G.; Kopylov, U.; Katsanos, K.; Halligan, S.; Gordon, H.; Gonzalez Lama, Y.; Ellul, P.; Eliakim, R.; Castiglione, F.; Burisch, J.; Borralho Nunes, P.; Bettenworth, D.; Baumgart, D. C.; Stoker, J.; European, C. s.; Colitis, O.; the European Society of, G.; Abdominal, R., ECCO-ESGAR Guideline for Diagnostic Assessment in IBD Part 2: IBD scores and general principles and technical aspects. J Crohns Colitis 2019, 13 (3), 273-284.

7. Biasci, D.; Lee, J. C.; Noor, N. M.; Pombal, D. R.; Hou, M.; Lewis, N.; Ahmad, T.; Hart, A.; Parkes, M.; McKinney, E. F.; Lyons, P. A.; Smith, K. G. C., A blood-based prognostic biomarker in IBD. Gut 2019, 68 (8), $1386-1395$.

8. Casale, J.; Crane, J. S., Biochemistry, Glycosaminoglycans. In StatPearls, Treasure Island (FL), 2021.

9. Morla, S., Glycosaminoglycans and Glycosaminoglycan Mimetics in Cancer and Inflammation. Int J Mol Sci 2019, 20 (8).

10. Murch, S. H.; MacDonald, T. T.; Walker-Smith, J. A.; Levin, M.; Lionetti, P.; Klein, N. J., Disruption of sulphated glycosaminoglycans in intestinal inflammation. Lancet 1993, 341 (8847), 711-4.

11. Naba, A.; Clauser, K. R.; Ding, H.; Whittaker, C. A.; Carr, S. A.; Hynes, R. O., The extracellular matrix: Tools and insights for the "omics" era. Matrix Biol 2016, 49, 10-24.

12. Naba, A.; Clauser, K. R.; Hoersch, S.; Liu, H.; Carr, S. A.; Hynes, R. O., The matrisome: in silico definition and in vivo characterization by proteomics of normal and tumor extracellular matrices. Mol Cell Proteomics 2012, 11 (4), M111 014647. 
13. Gomollon, F.; Dignass, A.; Annese, V.; Tilg, H.; Van Assche, G.; Lindsay, J. O.; Peyrin-Biroulet, L.; Cullen, G. J.; Daperno, M.; Kucharzik, T.; Rieder, F.; Almer, S.; Armuzzi, A.; Harbord, M.; Langhorst, J.; Sans, M.; Chowers, Y.; Fiorino, G.; Juillerat, P.; Mantzaris, G. J.; Rizzello, F.; Vavricka, S.; Gionchetti, P.; Ecco, 3rd European Evidence-based Consensus on the Diagnosis and Management of Crohn's Disease 2016: Part 1: Diagnosis and Medical Management. J Crohns Colitis 2017, 11 (1), 3-25.

14. Magro, F.; Gionchetti, P.; Eliakim, R.; Ardizzone, S.; Armuzzi, A.; Barreiro-de Acosta, M.; Burisch, J.; Gecse, K. B.; Hart, A. L.; Hindryckx, P.; Langner, C.; Limdi, J. K.; Pellino, G.; Zagorowicz, E.; Raine, T.; Harbord, M.; Rieder, F.; European, C. s.; Colitis, O., Third European Evidence-based Consensus on Diagnosis and Management of Ulcerative Colitis. Part 1: Definitions, Diagnosis, Extra-intestinal Manifestations, Pregnancy, Cancer Surveillance, Surgery, and Ileo-anal Pouch Disorders. J Crohns Colitis 2017, 11 (6), 649-670.

15. Adler, J.; Punglia, D. R.; Dillman, J. R.; Polydorides, A. D.; Dave, M.; Al-Hawary, M. M.; Platt, J. F.; McKenna, B. J.; Zimmermann, E. M., Computed tomography enterography findings correlate with tissue inflammation, not fibrosis in resected small bowel Crohn's disease. Inflamm Bowel Dis 2012, 18 (5), 849-56.

16. Pellino, G.; Nicolai, E.; Catalano, O. A.; Campione, S.; D'Armiento, F. P.; Salvatore, M.; Cuocolo, A.; Selvaggi, F., PET/MR Versus PET/CT Imaging: Impact on the Clinical Management of Small-Bowel Crohn's Disease. J Crohns Colitis 2016, 10 (3), 277-85.

17. Onali, S.; Calabrese, E.; Petruzziello, C.; Zorzi, F.; Sica, G.; Fiori, R.; Ascolani, M.; Lolli, E.; Condino, G.; Palmieri, G.; Simonetti, G.; Pallone, F.; Biancone, L., Small intestine contrast ultrasonography vs computed tomography enteroclysis for assessing ileal Crohn's disease. World J Gastroenterol 2012, 18 (42), 6088-95.

18. Pallotta, N.; Vincoli, G.; Montesani, C.; Chirletti, P.; Pronio, A.; Caronna, R.; Ciccantelli, B.; Romeo, E.; Marcheggiano, A.; Corazziari, E., Small intestine contrast ultrasonography (SICUS) for the detection of small bowel complications in crohn's disease: a prospective comparative study versus intraoperative findings. Inflamm Bowel Dis 2012, 18 (1), 74-84.

19. Kumar, S.; Hakim, A.; Alexakis, C.; Chhaya, V.; Tzias, D.; Pilcher, J.; Vlahos, J.; Pollok, R., Small intestinal contrast ultrasonography for the detection of small bowel complications in Crohn's disease: correlation with intraoperative findings and magnetic resonance enterography. J Gastroenterol Hepatol 2015, 30 (1), 86-91.

20. Ripolles, T.; Paredes, J. M.; Martinez-Perez, M. J.; Rimola, J.; Jauregui-Amezaga, A.; Bouzas, R.; Martin, G.; MorenoOsset, E., Ultrasonographic Changes at 12 Weeks of Anti-TNF Drugs Predict 1-year Sonographic Response and Clinical Outcome in Crohn's Disease: A Multicenter Study. Inflamm Bowel Dis 2016, 22 (10), 2465-73.

21. Novak, K. L.; Kaplan, G. G.; Panaccione, R.; Afshar, E. E.; Tanyingoh, D.; Swain, M.; Kellar, A.; Wilson, S., A Simple Ultrasound Score for the Accurate Detection of Inflammatory Activity in Crohn's Disease. Inflamm Bowel Dis 2017, 23 (11), $2001-2010$. 22. Limberg, B., [Diagnosis of chronic inflammatory bowel disease by ultrasonography]. Z Gastroenterol 1999, 37 (6), $495-508$.

23. Jing, J.; Wu, Y.; Zhang, H.; Zhang, Y.; Mu, J.; Luo, Y.; Zhuang, H., The establishment of a regression model from four modes of ultrasound to predict the activity of Crohn's disease. Sci Rep 2021, 11 (1), 77.

24. Bhatnagar, G.; Rodriguez-Justo, M.; Higginson, A.; Bassett, P.; Windsor, A.; Cohen, R.; Halligan, S.; Taylor, S. A., Inflammation and fibrosis in Crohn's disease: location-matched histological correlation of small bowel ultrasound features. Abdom Radiol (NY) 2021, 46 (1), 144-155.

25. Young, I. R.; Clarke, G. J.; Bailes, D. R.; Pennock, J. M.; Doyle, F. H.; Bydder, G. M., Enhancement of relaxation rate with paramagnetic contrast agents in NMR imaging. J Comput Tomogr 1981, 5 (6), 543-7.

26. Niendorf, H. P.; Haustein, J.; Cornelius, I.; Alhassan, A.; Clauss, W., Safety of gadolinium-DTPA: extended clinical experience. Magn Reson Med 1991, 22 (2), 222-8; discussion 229-32.

27. Laniado, M.; Kornmesser, W.; Hamm, B.; Clauss, W.; Weinmann, H. J.; Felix, R., MR imaging of the gastrointestinal tract: value of Gd-DTPA. AJR Am J Roentgenol 1988, 150 (4), 817-21. 
28. Vlahos, L.; Gouliamos, A.; Clauss, W.; Kalovidouris, A.; Athanasopoulou, A.; Petroulakis, A.; Hadjiioannou, A.; Papavasiliou, C., Gd-DTPA as an intestinal contrast agent for MR imaging of the lower abdomen: phase III clinical trial. Gastrointest Radiol 1992, 17 (4), 300-4.

29. Rollandi, G. A.; Martinoli, C.; Conzi, R.; Cittadini, G.; Molinari, F.; Bertolotto, M.; Talenti, A.; Curone, P., [Magnetic resonance imaging of the small intestine and colon in Crohn's disease]. Radiol Med 1996, 91 (1-2), 81-5.

30. Aime, S.; Caravan, P., Biodistribution of gadolinium-based contrast agents, including gadolinium deposition. J Magn Reson Imaging 2009, 30 (6), 1259-67.

31. Holm Nielsen, S.; Jonasson, L.; Kalogeropoulos, K.; Karsdal, M. A.; Reese-Petersen, A. L.; Auf dem Keller, U.; Genovese, F.; Nilsson, J.; Goncalves, I., Exploring the role of extracellular matrix proteins to develop biomarkers of plaque vulnerability and outcome. J Intern Med 2020, 287 (5), 493-513.

32. Uca, Y. O.; Hallmann, D.; Hesse, B.; Seim, C.; Stolzenburg, N.; Pietsch, H.; Schnorr, J.; Taupitz, M., Microdistribution of Magnetic Resonance Imaging Contrast Agents in Atherosclerotic Plaques Determined by LA-ICP-MS and SR-muXRF Imaging. Mol Imaging Biol 2021, 23 (3), 382-393.

33. Chow, A. M.; Tan, M.; Gao, D. S.; Fan, S. J.; Cheung, J. S.; Man, K.; Lu, Z. R.; Wu, E. X., Molecular MRI of liver fibrosis by a peptide-targeted contrast agent in an experimental mouse model. Invest Radiol 2013, 48 (1), $46-54$.

34. Ye, F.; Wu, X.; Jeong, E. K.; Jia, Z.; Yang, T.; Parker, D.; Lu, Z. R., A peptide targeted contrast agent specific to fibrinfibronectin complexes for cancer molecular imaging with MRI. Bioconjug Chem 2008, 19 (12), 2300-3.

35. Taylor, S. A.; Mallett, S.; Bhatnagar, G.; Baldwin-Cleland, R.; Bloom, S.; Gupta, A.; Hamlin, P. J.; Hart, A. L.; Higginson, A.; Jacobs, I.; McCartney, S.; Miles, A.; Murray, C. D.; Plumb, A. A.; Pollok, R. C.; Punwani, S.; Quinn, L.; Rodriguez-Justo, M.; Shabir, Z.; Slater, A.; Tolan, D.; Travis, S.; Windsor, A.; Wylie, P.; Zealley, I.; Halligan, S.; investigators, M. s., Diagnostic accuracy of magnetic resonance enterography and small bowel ultrasound for the extent and activity of newly diagnosed and relapsed Crohn's disease (METRIC): a multicentre trial. Lancet Gastroenterol Hepatol 2018, 3 (8), 548-558.

36. Quaia, E.; Cabibbo, B.; Sozzi, M.; Gennari, A. G.; Pontello, M.; Degrassi, F.; Cova, M. A., Biochemical markers and MR imaging findings as predictors of crohn disease activity in patients scanned by contrast-enhanced MR enterography. Acad Radiol 2014, 21 (10), 1225-32.

37. Li, X. H.; Mao, R.; Huang, S. Y.; Sun, C. H.; Cao, Q. H.; Fang, Z. N.; Zhang, Z. W.; Huang, L.; Lin, J. J.; Chen, Y. J.; Rimola, J.; Rieder, F.; Chen, M. H.; Feng, S. T.; Li, Z. P., Characterization of Degree of Intestinal Fibrosis in Patients with Crohn Disease by Using Magnetization Transfer MR Imaging. Radiology 2018, 287 (2), 494-503.

38. Wagner, M.; Ko, H. M.; Chatterji, M.; Besa, C.; Torres, J.; Zhang, X.; Panchal, H.; Hectors, S.; Cho, J.; Colombel, J. F.; Harpaz, N.; Taouli, B., Magnetic Resonance Imaging Predicts Histopathological Composition of Ileal Crohn's Disease. J Crohns Colitis 2018, 12 (6), 718-729.

39. Biernacka, K. B.; Baranska, D.; Grzelak, P.; Czkwianianc, E.; Szabelska-Zakrzewska, K., Up-to-date overview of imaging techniques in the diagnosis and management of inflammatory bowel diseases. Prz Gastroenterol 2019, 14 (1), $19-25$.

40. Pallotta, N.; Tomei, E.; Viscido, A.; Calabrese, E.; Marcheggiano, A.; Caprilli, R.; Corazziari, E., Small intestine contrast ultrasonography: an alternative to radiology in the assessment of small bowel disease. Inflamm Bowel Dis 2005, 11 (2), 146-53.

41. Novak, K. L.; Nylund, K.; Maaser, C.; Petersen, F.; Kucharzik, T.; Lu, C.; Allocca, M.; Maconi, G.; de Voogd, F.; Christensen, B.; Vaughan, R.; Palmela, C.; Carter, D.; Wilkens, R., Expert Consensus on Optimal Acquisition and Development of the International Bowel Ultrasound Segmental Activity Score [IBUS-SAS]: A Reliability and Inter-rater Variability Study on Intestinal Ultrasonography in Crohn's Disease. J Crohns Colitis 2021, 15 (4), 609-616.

42. Basu, S.; Zhuang, H.; Torigian, D. A.; Rosenbaum, J.; Chen, W.; Alavi, A., Functional imaging of inflammatory diseases using nuclear medicine techniques. Semin Nucl Med 2009, 39 (2), 124-45.

43. Stidham, R. W.; Xu, J.; Johnson, L. A.; Kim, K.; Moons, D. S.; McKenna, B. J.; Rubin, J. M.; Higgins, P. D., Ultrasound elasticity imaging for detecting intestinal fibrosis and inflammation in rats and humans with Crohn's disease. Gastroenterology 2011, 141 (3), 819-826 e1. 
44. Fraquelli, M.; Branchi, F.; Cribiu, F. M.; Orlando, S.; Casazza, G.; Magarotto, A.; Massironi, S.; Botti, F.; Contessini-Avesani, E.; Conte, D.; Basilisco, G.; Caprioli, F., The Role of Ultrasound Elasticity Imaging in Predicting Ileal Fibrosis in Crohn's Disease Patients. Inflamm Bowel Dis 2015, 21 (11), 2605-12.

45. Baumgart, D. C.; Muller, H. P.; Grittner, U.; Metzke, D.; Fischer, A.; Guckelberger, O.; Pascher, A.; Sack, I.; Vieth, M.; Rudolph, B., US-based Real-time Elastography for the Detection of Fibrotic Gut Tissue in Patients with Stricturing Crohn Disease. Radiology 2015, 275 (3), 889-99.

46. Serra, C.; Rizzello, F.; Pratico, C.; Felicani, C.; Fiorini, E.; Brugnera, R.; Mazzotta, E.; Giunchi, F.; Fiorentino, M.; D'Errico, A.; Morselli-Labate, A. M.; Mastroroberto, M.; Campieri, M.; Poggioli, G.; Gionchetti, P., Real-time elastography for the detection of fibrotic and inflammatory tissue in patients with stricturing Crohn's disease. J Ultrasound 2017, 20 (4), $273-284$.

47. Wilkens, R.; Hagemann-Madsen, R. H.; Peters, D. A.; Nielsen, A. H.; Norager, C. B.; Glerup, H.; Krogh, K., Validity of Contrast-enhanced Ultrasonography and Dynamic Contrast-enhanced MR Enterography in the Assessment of Transmural Activity and Fibrosis in Crohn's Disease. J Crohns Colitis 2018, 12 (1), 48-56.

48. Dillman, J. R.; Stidham, R. W.; Higgins, P. D.; Moons, D. S.; Johnson, L. A.; Keshavarzi, N. R.; Rubin, J. M., Ultrasound shear wave elastography helps discriminate low-grade from high-grade bowel wall fibrosis in ex vivo human intestinal specimens. J Ultrasound Med 2014, 33 (12), 2115-23.

49. Lu, C.; Gui, X.; Chen, W.; Fung, T.; Novak, K.; Wilson, S. R., Ultrasound Shear Wave Elastography and Contrast Enhancement: Effective Biomarkers in Crohn's Disease Strictures. Inflamm Bowel Dis 2017, 23 (3), 421-430.

50. Chen, Y. J.; Mao, R.; Li, X. H.; Cao, Q. H.; Chen, Z. H.; Liu, B. X.; Chen, S. L.; Chen, B. L.; He, Y.; Zeng, Z. R.; Ben-Horin, S.; Rimola, J.; Rieder, F.; Xie, X. Y.; Chen, M. H., Real-Time Shear Wave Ultrasound Elastography Differentiates Fibrotic from Inflammatory Strictures in Patients with Crohn's Disease. Inflamm Bowel Dis 2018, 24 (10), $2183-2190$.

51. Goertz, R. S.; Lueke, C.; Schellhaas, B.; Pfeifer, L.; Wildner, D.; Neurath, M. F.; Strobel, D., Acoustic radiation force impulse (ARFI) shear wave elastography of the bowel wall in healthy volunteers and in ulcerative colitis. Acta Radiol Open 2019, 8 (4), 2058460119840969.

52. Venkatesh, S. K.; Ehman, R. L., Magnetic resonance elastography of abdomen. Abdom Imaging 2015, 40 (4), 745-59.

53. Reiter, R.; Loch, F. N.; Kamphues, C.; Bayerl, C.; Marticorena Garcia, S. R.; Siegmund, B.; Kuhl, A. A.; Hamm, B.; Braun, J.; Sack, I.; Asbach, P., Feasibility of Intestinal MR Elastography in Inflammatory Bowel Disease. J Magn Reson Imaging 2021. 54. Gordon, I. O.; Bettenworth, D.; Bokemeyer, A.; Srivastava, A.; Rosty, C.; de Hertogh, G.; Robert, M. E.; Valasek, M. A.; Mao, R.; Li, J.; Harpaz, N.; Borralho, P.; Pai, R. K.; Odze, R.; Feakins, R.; Parker, C. E.; Guizzetti, L.; Nguyen, T.; Shackelton, L. M.; Sandborn, W. J.; Jairath, V.; Baker, M.; Bruining, D.; Fletcher, J. G.; Feagan, B. G.; Pai, R. K.; Rieder, F.; Stenosis, T.; Anti-Fibrotic Research, C., International consensus to standardise histopathological scoring for small bowel strictures in Crohn's disease. Gut 2021.

55. Movat, H. Z., Demonstration of all connective tissue elements in a single section; pentachrome stains. AMA Arch Pathol 1955, 60 (3), 289-95.

56. Goldner, J., A modification of the masson trichrome technique for routine laboratory purposes. Am J Pathol 1938, 14 (2), 23743.

57. Lakatos, G.; Sipos, F.; Miheller, P.; Hritz, I.; Varga, M. Z.; Juhasz, M.; Molnar, B.; Tulassay, Z.; Herszenyi, L., The behavior of matrix metalloproteinase-9 in lymphocytic colitis, collagenous colitis and ulcerative colitis. Pathol Oncol Res 2012, 18 (1), 85-91.

58. Fonseca-Camarillo, G.; Furuzawa-Carballeda, J.; Martinez-Benitez, B.; Barreto-Zuniga, R.; Yamamoto-Furusho, J. K., Increased expression of extracellular matrix metalloproteinase inducer (EMMPRIN) and MMP10, MMP23 in inflammatory bowel disease: Cross-sectional study. Scand J Immunol 2021, 93 (1), e12962.

59. de Bruyn, J. R.; van den Brink, G. R.; Steenkamer, J.; Buskens, C. J.; Bemelman, W. A.; Meisner, S.; Muncan, V.; Te Velde, A. A.; D'Haens, G. R.; Wildenberg, M. E., Fibrostenotic Phenotype of Myofibroblasts in Crohn's Disease is Dependent on Tissue Stiffness and Reversed by LOX Inhibition. J Crohns Colitis 2018, 12 (7), 849-859. 
60. Ning, L.; Li, S.; Gao, J.; Ding, L.; Wang, C.; Chen, W.; Shan, G.; Zhang, F.; Yu, J.; Xu, G., Tenascin-C Is Increased in Inflammatory Bowel Disease and Is Associated with response to Infliximab Therapy. Biomed Res Int 2019, $2019,1475705$.

61. Derkacz, A.; Olczyk, P.; Jura-Poltorak, A.; Olczyk, K.; Komosinska-Vassev, K., The Diagnostic Usefulness of Circulating Profile of Extracellular Matrix Components: Sulfated Glycosaminoglycans (sGAG), Hyaluronan (HA) and Extracellular Part of Syndecan-1 (sCD138) in Patients with Crohn's Disease and Ulcerative Colitis. J Clin Med 2021, 10 (8).

62. Goffin, L.; Fagagnini, S.; Vicari, A.; Mamie, C.; Melhem, H.; Weder, B.; Lutz, C.; Lang, S.; Scharl, M.; Rogler, G.; Chvatchko, Y.; Hausmann, M., Anti-MMP-9 Antibody: A Promising Therapeutic Strategy for Treatment of Inflammatory Bowel Disease Complications with Fibrosis. Inflamm Bowel Dis 2016, 22 (9), 2041-57.

63. Mortensen, J. H.; Godskesen, L. E.; Jensen, M. D.; Van Haaften, W. T.; Klinge, L. G.; Olinga, P.; Dijkstra, G.; Kjeldsen, J.; Karsdal, M. A.; Bay-Jensen, A. C.; Krag, A., Fragments of Citrullinated and MMP-degraded Vimentin and MMPdegraded Type III Collagen Are Novel Serological Biomarkers to Differentiate Crohn's Disease from Ulcerative Colitis. J Crohns Colitis 2015, 9 (10), 863-72.

64. Kapsoritakis, A. N.; Kapsoritaki, A. I.; Davidi, I. P.; Lotis, V. D.; Manolakis, A. C.; Mylonis, P. I.; Theodoridou, A. T.; Germenis, A. E.; Potamianos, S. P., Imbalance of tissue inhibitors of metalloproteinases (TIMP) - 1 and - 4 serum levels, in patients with inflammatory bowel disease. BMC Gastroenterol 2008, 8, 55.

65. Stidham, R. W.; Wu, J.; Shi, J.; Lubman, D. M.; Higgins, P. D., Serum Glycoproteome Profiles for Distinguishing Intestinal Fibrosis from Inflammation in Crohn's Disease. PLoS One 2017, 12 (1), e0170506.

66. van Haaften, W. T.; Mortensen, J. H.; Karsdal, M. A.; Bay-Jensen, A. C.; Dijkstra, G.; Olinga, P., Misbalance in type III collagen formation/degradation as a novel serological biomarker for penetrating (Montreal B3) Crohn's disease. Aliment Pharmacol Ther 2017, 46 (1), 26-39.

67. Wu, J.; Lubman, D. M.; Kugathasan, S.; Denson, L. A.; Hyams, J. S.; Dubinsky, M. C.; Griffiths, A. M.; Baldassano, R. N.; Noe, J. D.; Rabizadeh, S.; Gulati, A. S.; Rosh, J. R.; Crandall, W. V.; Higgins, P. D. R.; Stidham, R. W., Serum Protein Biomarkers of Fibrosis Aid in Risk Stratification of Future Stricturing Complications in Pediatric Crohn's Disease. Am J Gastroenterol 2019, 114 (5), 777-785.

68. Targan, S. R.; Landers, C. J.; Yang, H.; Lodes, M. J.; Cong, Y.; Papadakis, K. A.; Vasiliauskas, E.; Elson, C. O.; Hershberg, R. M., Antibodies to CBir1 flagellin define a unique response that is associated independently with complicated Crohn's disease. Gastroenterology 2005, 128 (7), 2020-8.

69. Mow, W. S.; Vasiliauskas, E. A.; Lin, Y. C.; Fleshner, P. R.; Papadakis, K. A.; Taylor, K. D.; Landers, C. J.; AbreuMartin, M. T.; Rotter, J. I.; Yang, H.; Targan, S. R., Association of antibody responses to microbial antigens and complications of small bowel Crohn's disease. Gastroenterology 2004, 126 (2), 414-24.

70. Pellino, G.; Pallante, P.; Selvaggi, F., Novel biomarkers of fibrosis in Crohn's disease. World J Gastrointest Pathophysiol 2016, 7 (3), 266-75.

71. Paul, S.; Boschetti, G.; Rinaudo-Gaujous, M.; Moreau, A.; Del Tedesco, E.; Bonneau, J.; Presles, E.; Mounsef, F.; Clavel, L.; Genin, C.; Flourie, B.; Phelip, J. M.; Nancey, S.; Roblin, X., Association of Anti-glycan Antibodies and Inflammatory Bowel Disease Course. J Crohns Colitis 2015, 9 (6), 445-51.

72. Giuffrida, P.; Pinzani, M.; Corazza, G. R.; Di Sabatino, A., Biomarkers of intestinal fibrosis - one step towards clinical trials for stricturing inflammatory bowel disease. United European Gastroenterol J 2016, 4 (4), 523-30.

73. Di Sabatino, A.; Ciccocioppo, R.; Armellini, E.; Morera, R.; Ricevuti, L.; Cazzola, P.; Fulle, I.; Corazza, G. R., Serum bFGF and VEGF correlate respectively with bowel wall thickness and intramural blood flow in Crohn's disease. Inflamm Bowel Dis 2004, 10 (5), 573-7.

74. Kumagai, S.; Ohtani, H.; Nagai, T.; Funa, K.; Hiwatashi, N. O.; Shimosegawa; Nagura, H., Platelet-derived growth factor and its receptors are expressed in areas of both active inflammation and active fibrosis in inflammatory bowel disease. Tohoku J Exp Med 2001, 195 (1), 21-33. 
75. Matusiewicz, M.; Neubauer, K.; Mierzchala-Pasierb, M.; Gamian, A.; Krzystek-Korpacka, M., Matrix metalloproteinase9: its interplay with angiogenic factors in inflammatory bowel diseases. Dis Markers 2014, 2014, 643645.

76. Murakami, Y.; Toyoda, H.; Tanaka, M.; Kuroda, M.; Harada, Y.; Matsuda, F.; Tajima, A.; Kosaka, N.; Ochiya, T.; Shimotohno, K., The progression of liver fibrosis is related with overexpression of the miR-199 and 200 families. PLoS One 2011, 6 (1), e16081.

77. Mehta, S. J.; Lewis, A.; Nijhuis, A.; Jeffery, R.; Biancheri, P.; Di Sabatino, A.; Feakins, R.; Silver, A.; Lindsay, J. O., Epithelial down-regulation of the miR-200 family in fibrostenosing Crohn's disease is associated with features of epithelial to mesenchymal transition. J Cell Mol Med 2018, 22 (11), 5617-5628.

78. Lewis, A.; Mehta, S.; Hanna, L. N.; Rogalski, L. A.; Jeffery, R.; Nijhuis, A.; Kumagai, T.; Biancheri, P.; Bundy, J. G.; Bishop, C. L.; Feakins, R.; Di Sabatino, A.; Lee, J. C.; Lindsay, J. O.; Silver, A., Low Serum Levels of MicroRNA-19 Are Associated with a Stricturing Crohn's Disease Phenotype. Inflamm Bowel Dis 2015, 21 (8), 1926-34.

79. Nijhuis, A.; Biancheri, P.; Lewis, A.; Bishop, C. L.; Giuffrida, P.; Chan, C.; Feakins, R.; Poulsom, R.; Di Sabatino, A.; Corazza, G. R.; MacDonald, T. T.; Lindsay, J. O.; Silver, A. R., In Crohn's disease fibrosis-reduced expression of the miR-29 family enhances collagen expression in intestinal fibroblasts. Clin Sci (Lond) 2014, 127 (5), 341-50.

80. de Bruyn, J. R.; Becker, M. A.; Steenkamer, J.; Wildenberg, M. E.; Meijer, S. L.; Buskens, C. J.; Bemelman, W. A.; Lowenberg, M.; Ponsioen, C. Y.; van den Brink, G. R.; D'Haens, G. R., Intestinal fibrosis is associated with lack of response to Infliximab therapy in Crohn's disease. PLoS One 2018, 13 (1), e0190999.

81. Paramsothy, S.; Rosenstein, A. K.; Mehandru, S.; Colombel, J. F., The current state of the art for biological therapies and new small molecules in inflammatory bowel disease. Mucosal Immunol 2018, 11 (6), 1558-1570.

82. Carlo Cosimo Quattrocchi, A. J. V. D. M., Gadolinium Retention in Brain and Body: Clinical and Preclinical Evidence. In Imaging in Nephrology, Granata A., B. M., Ed. Springer, Cham: 2021.

83. Vajravelu, R. K.; Copelovitch, L.; Osterman, M. T.; Scott, F. I.; Mamtani, R.; Lewis, J. D.; Denburg, M. R., Inflammatory Bowel Diseases Are Associated With an Increased Risk for Chronic Kidney Disease, Which Decreases With Age. Clin Gastroenterol Hepatol 2020, 18 (10), 2262-2268.

84. Wagner, B.; Drel, V.; Gorin, Y., Pathophysiology of gadolinium-associated systemic fibrosis. Am J Physiol Renal Physiol 2016, 311 (1), F1-F11.

85. Maaser, C.; Petersen, F.; Helwig, U.; Fischer, I.; Roessler, A.; Rath, S.; Lang, D.; Kucharzik, T.; German, I. B. D. S. G.; the, T.; group, U. C. s.; German, I. B. D. S. G.; Trust; group, U. C. s., Intestinal ultrasound for monitoring therapeutic response in patients with ulcerative colitis: results from the TRUST\&UC study. Gut 2020, 69 (9), 1629-1636.

86. Crohn, B. B.; Ginzburg, L.; Oppenheimer, G. D., Landmark article Oct 15, 1932. Regional ileitis. A pathological and clinical entity. By Burril B. Crohn, Leon Ginzburg, and Gordon D. Oppenheimer. JAMA 1984, 251 (1), 73-9.

87. Weakley, F. L.; Turnbull, R. B., Recognition of regional ileitis in the operating room. Dis Colon Rectum 1971, 14 (1), 17-23.

88. Kredel, L. I.; Siegmund, B., Adipose-tissue and intestinal inflammation - visceral obesity and creeping fat. Front Immunol 2014, 5,462 .

89. Branchi, F.; Caprioli, F.; Orlando, S.; Conte, D.; Fraquelli, M., Non-invasive evaluation of intestinal disorders: The role of elastographic techniques. World J Gastroenterol 2017, 23 (16), 2832-2840.

90. Juillerat, P.; Manz, M.; Sauter, B.; Zeitz, J.; Vavricka, S. R.; Swiss Ibdnet, a. o. w. g. o. t. S. S. o. G., Therapies in Inflammatory Bowel Disease Patients with Extraintestinal Manifestations. Digestion 2020, 101 Suppl 1, 83-97. 